\title{
On Economic Dispatch of Electrical Power
}

\author{
K. C. Sravanthi \\ PG student \\ Electrical and Electronics \\ Engineering Department \\ VR Siddhartha Engineering College \\ Vijayawada-520007
}

\author{
M. S. Krishnarayalu \\ Professor \\ Electrical and Electronics \\ Engineering Department \\ VR Siddhartha Engineering College \\ Vijayawada-520007
}

\begin{abstract}
Economic dispatch of electrical power is very important in the sense it saves lot of money by employing an optimization method based on the required performance index resulting in optimal power flow. In classical Economic Dispatch (ED) method all units are committed. In Unit Commitment (UC) method all the units need not be committed and they are committed based on the load demand during that interval. In Unit Commitment with Economic Dispatch (UCED) method, required number of units is committed like in UC and optimization method of ED is employed to find optimal power flow for this state. As a case study a ten-unit power system is considered. ED and UC problems of this system are solved using PSO algorithm. UCED method is also implemented for the same system. The results show that UCED method is more efficient.
\end{abstract}

\section{General Terms}

Electrical Power, Fuel, Optimization.

\section{Keywords}

Economic Dispatch, Unit Commitment, Unit Commitment with Economic Dispatch, Particle Swarm Optimization, Tenunit power system.

\section{INTRODUCTION}

Efficient equipment minimizes cost. Engineers have succeeded in increasing the efficiency of the major components of power system namely boilers, turbines, transformers and generators. What remains is minimization of operational cost. This can be achieved by minimizing the fuel consumption so that the cost of power delivered is minimum. Fuel consumption of each unit depends on its power generation. More power generation requires more fuel consumption. Hence it is required to determine the optimal unit generations for a given load demand such that the total fuel cost is minimum. Our objective is computing the generation schedules of different units so that the cost of power delivered is minimum with minimum total fuel cost for a given load demand. This is called economic dispatch (ED) or optimal power flow (OPF) problem. Unit Commitment (UC) method is an alternative to ED. In ED all the units are committed whereas in UC only the units that can supply the load demand are committed resulting in better efficiency.

The input fuel cost is a nonlinear and complex equation corresponding to each generating unit. To optimize these complex equations, different optimization techniques are used. Basic methods like Lagrangian multiplier method, Lambda-iteration method, Gradient methods, Dynamic Programming method and Base point and Participation factors are used for solving the Economic Dispatch. In all the basic methods of ED the Incremental Fuel Cost (IFC) plays a major role, used to form the co-ordination equation. In Unit
Commitment, all the units need not be committed all the time like in ED. Here only minimum number of units that meet the load demand will be committed so that the fuel cost is minimum. This also involves the complex and non-linear input cost function. To optimize this UC complex objective function basic methods like Dynamic Programming Method, Lagrange Relaxation method are used in general. Unit Commitment also involves the start- up costs (SUC) and shutdown costs while committing and de-committing the units they come into action $[1,2]$.

ED and UC are the established methods, where whole number of units is committed in ED and efficient, relevant units are committed in UC [3]. Now UC and ED are mixed to get better results. Unit Commitment with Economic Dispatch (UCED), is a combination of UC and ED. In UCED method minimum number of units is committed like in UC. Then optimal generations are computed employing the coordination equation of these units like in ED resulting in more fuel economy.

Particle Swarm Optimization (PSO), one of the stochastic and heuristic methods, is a very efficient solver and a flexible worker on computers [4]. PSO has been introduced by Kennedy and Eberhart. It is based on social behavior of organisms such as fish schooling and bird flocking. The main advantage, of PSO, is able to find the global optimum simultaneously with local optimums. The rate of change in position, Velocity is found in terms of Cognitive and Social components and new position is set based on the velocity obtained. This method is easy to compute as it doesn't involve crossover, mutation operations. Dimensionality problem is less in PSO when compared to other heuristic methods $[5,6]$.

In this paper, ED and UC problems of a ten-unit power system are solved using PSO $[3,7]$. Then it is also worked out using UCED method.

\section{FORMULATION OF ED PROBLEM}

The economic dispatch is a constrained optimization problem, involving objective function and the constraint. The objective function is the input fuel cost function and the constraint is an equality constraint that matches load demand and transmission losses with power generation. The resulting augmented cost function is minimized using Lagrange method [8].

\subsection{Objective Function}

The objective of the Economic Dispatch is to reduce the input fuel cost by satisfying the constraint, involving all the units. Involving all the units' means even at the low loads each unit must be operated at minimum power bound. For an 'N' unit system the total fuel cost (TFC) may be taken as objective function for optimal power flow.

$T F C, F_{t}=\sum_{i=1}^{N} F_{i}\left(P_{i}\right), \quad \$ / \mathrm{h}$ 


$$
=\sum_{i=1}^{N}\left(a_{i}+b_{i} * P_{i}+c_{i} * P_{i}^{2}\right)
$$

where $F_{i}$, input fuel cost of $i^{\text {th }}$ unit, represented in terms of cost coefficients as

$F_{i}=a_{i}+b_{i} * P_{i}+c_{i} * P_{i}^{2}$

Objective function:

$\min F_{t}=\sum_{i=1}^{N}\left(a_{i}+b_{i} * P_{i}+c_{i} * P_{i}^{2}\right), \quad \$ / \mathrm{h}$

\subsection{Constraint and Bounds}

The total power generation of the units/plants must be equal to the total load demand if the transmission losses are ignored. Hence the constraint is

$$
\begin{gathered}
\sum_{i=1}^{N} P_{i}=P_{D} \\
\Phi=P_{D}-\sum_{i=1}^{N} P_{i}=0 \text { - Equality Constraint }
\end{gathered}
$$

where $P_{i}$ is Power outputs of $i^{\text {th }}$ unit and $P_{D}$ is the total load demand of the power system.

The Bounds of the generating units are given in MW as:

$$
P_{i_{\text {min }}} \leq P_{i} \leq P_{i_{\max }}
$$

\subsection{Coordination Equation}

The Augmented Cost Function is the combination of Objective Function and Constraint. It is represented as Lagrange function using a Lagrangian multiplier $\lambda$.

$$
\begin{gathered}
\mathcal{L}=F_{t}+\lambda * \Phi \\
\mathcal{L}=\left(\sum_{i=1}^{N}\left(a_{i}+b_{i} * P_{i}+c_{i} * P_{i}^{2}\right)\right) \\
+\lambda *\left(P_{D}-\sum_{i=1}^{N} P_{i}\right)
\end{gathered}
$$

Basically, for optimization the first order derivative of Lagrange function with respect to $\mathrm{P}_{\mathrm{i}}$ must be equal to zero.

$$
\frac{d \mathcal{L}}{d P_{i}}=0
$$

On simplification,

$$
\lambda=\frac{d F_{i}}{d P_{i}}=I F C \text { of power system }, \$ / \mathrm{MWh}
$$

(9) is the Coordination Equation for determining the optimal power flow of this loss less power system.

\section{FORMULATION OF UC PROBLEM}

The Unit Commitment is also a constrained optimization problem, involving objective function and the constraint similar to ED. In general, more the units more the running costs. In UC number of units committed depends on total load demand $\mathrm{P}_{\mathrm{D}}$. Here all units need not be committed, commit the minimum number of units satisfying the $P_{D}$ resulting in optimal power flow. TFC includes fuel costs of the committed units only. The committed units are indicated by a binary matrix $U_{i}$, which plays a crucial role.

\subsection{Objective Function}

The objective of the Unit Commitment is to reduce the TFC by satisfying the constraint, involving only necessary units. For the ' $\mathrm{N}$ ' unit system the objective function for UC is framed as:
Objective Function:

$$
\min F=\sum_{i=1}^{N}\left(\left(a_{i}+b_{i} * P_{i}+c_{i} * P_{i}^{2}\right) * U_{i}\right),
$$

\subsection{Constraint and Bounds}

The total power generation of the units must be equal to the load demand if the transmission losses are ignored in UC problem also. Here the Constraint is

$$
\begin{gathered}
\sum_{i=1}^{N} P_{i} * U_{i}=P_{D} \\
\Phi=P_{D}-\sum_{i=1}^{N} P_{i} * U_{i}=0
\end{gathered}
$$

The Bounds of the generating units are given in MW if they are committed:

$$
P_{i_{\min }} \leq P_{i} \leq P_{i_{\max }}
$$

\section{FORMULATION OF UCED PROBLEM}

UCED method is a combination of UC and ED methods. Here also minimum number of units is committed satisfying the $P_{D}$ in that time interval like in UC. Efficiency (like full load IFC) may be considered while committing units of similar capacity. Also units should be committed resulting in lesser number of switchovers so that startup costs are less. The objective function, constraints and bounds will be like in UC. Then the optimal power flow can be obtained using the coordination equation of the units committed like in ED. This is not a trial and error method and gives a unique solution obtained by solving linear simultaneous equations.

\section{INTRODUCTION TO PARTICLE SWARM OPTIMIZATION}

Particle Swarm Optimization (PSO), the name itself describes that the method, based on behavior of swarm like bird flocking and fish schooling is a population based stochastic and heuristic optimization method. It is developed by Dr. Kennedy and Dr. Eberhart in 1995. PSO is an optimization tool that finds the minimum or maximum value of the objective function. PSO terminology mainly includes Fitness Function, Particles, Population, Velocities and Positions of particles. The total size of the Particles is Population. The particles in PSO are nothing but swarm. The swarm has the capability to move in multi-dimensions. Hence the optimal search in PSO is also multi-dimensional. Each individual/particle can have its own position. The advantage of PSO is each individual has the capability to know the behavior of other individual's position and velocity. During particles' run each individual can move with certain velocity based on individual and neighbors' experience. Particles change from their old position to new position by their personal and neighbors' experience.

The positions and velocities of particles in PSO are represented as vectors $x$ and $v$ whose size is equal to population. The positional vector $x$ with the population size $i$ is given by $x=\left(x_{1}, x_{2}, x_{3}, \ldots, x_{i}\right)^{\prime}$, for which the $\mathrm{i}^{\text {th }}$ particle is represented as $x_{i}^{(t)}=\left(x_{i 1}^{(t)}, x_{i 2}^{(t)}, x_{i 3}^{(t)}, \ldots, x_{i d}^{(t)}\right)$ where $d$ is number of dimensions. Now the personal best of an individuali, $p_{\text {best }_{i}}$ is the decided from the fitness function of last and present generation represented as $p_{\text {best }_{i}}=$ $\left(p_{\text {best }_{i 1}}, p_{\text {best }_{i 2}}, \ldots, p_{\text {best }_{i d}}\right)$. The particle which is having the highest fitness value is the global best, $g_{\text {best }_{d}}$. 
The velocity of the particle required to reach a new position of the particle in PSO is [9]

$$
\begin{gathered}
v_{i d}^{(t+1)}=w^{(t+1)} \cdot v_{i d}^{(t)}+c_{1} * \text { rand }_{1} *\left(\text { pbest }_{i d}-x_{i d}^{(t)}\right) \\
+c_{2} * \text { rand }_{2} *\left(\text { gbest }_{d}-x_{i d}^{(t)}\right)
\end{gathered}
$$

The new velocities include mainly two components called cognitive component and social component. The cognitive component includes an acceleration constant $c_{1}$, a random number within $(0,1)$ and personal experience of particles. Similarly, the social component includes an acceleration constant $c_{2}$, another random number within $(0,1)$ and neighboring experience of particles. The acceleration constants for greater convergence are selected as $c_{1}=c_{2}=2$.

Let $t$ is number of iterations/generations and step time $\Delta t=1 \mathrm{~s}$. Then the change in position is given by

$$
\begin{aligned}
x_{i d}^{(t+1)}= & x_{i d}^{(t)}+v_{i d}^{(t+1)} * \Delta t \\
& =x_{i d}^{(t)}+v_{i d}^{(t+1)}
\end{aligned}
$$

The minimum and maximum values of the velocities are to be assumed based on the problem and the limits are set to these velocities. Generally, the limits for velocities are $10-20 \%$ of the individuals.

Then the Inertia Weight $w$ needs to be changed for each iteration as it provides a balance between global and local best solutions. In general, the inertia weight is given by

$$
w^{(t+1)}=w_{\max }-\frac{w_{\max }-w_{\min }}{\text { iter }_{\max }} * \operatorname{iter}(t)
$$

$w$ is linearly decreased from $0.9\left(\mathrm{w}_{\max }\right)$ to $0.4\left(\mathrm{w}_{\min }\right)$, where iter $_{\max }$ is maximum number of iterations and iter $(t)$ is current iteration.

Let ' $d$ ' be number of dimensions and ' $i$ ' be the number of individuals/ particles. For ED, d equals number of units ' $N$ '. Then the position vector in ED is given by $P_{i}^{(t)}=$ $\left(P_{i 1}^{(t)}, P_{i 2}^{(t)}, P_{i 3}^{(t)}, \ldots, P_{i d}^{(t)}\right)$ are randomly selected values.

$$
P_{i}=\left[\begin{array}{ccc}
P_{11} & \cdots & P_{1 N} \\
\vdots & \ddots & \vdots \\
P_{i 1} & \cdots & P_{i N}
\end{array}\right]_{(n * d)}
$$

\subsection{Fitness Function}

The Fitness function formation can be of two types. One includes both Objective Function and Constraint and the other is only Objective Function where the constraint is satisfied first. The Fitness function of the first type, $f$ is given by:

$$
\begin{gathered}
f=\frac{1}{F_{\text {cost }}+P_{c}} \\
\text { where } F_{\text {cost }}=\left(\sum_{i=1}^{N}\left(a_{i}+b_{i} * P_{i}+c_{i} * P_{i}^{2}\right) * U_{i}\right)
\end{gathered}
$$

In ED all elements of $U_{i}$ are unity.

In UC elements of $U_{i}$ are unity or zero depending on commitment.

$$
P_{c}=1+\left(\sum_{i=1}^{N} P_{i}-P_{D}\right)^{2}
$$

\section{$F_{\text {max }}-$ TFC at maximum power bounds}

$$
F_{\text {min }}-\text { TFC at minimum power bounds }
$$

Here, to get minimum TFC while satisfying constraint the value of $f$ must be maximum. The value of $P_{c}$ is about 1 and the $F_{\text {cost }}$ value is lowest.
The algorithm when PSO applied to ED is [5, 10]:

1. Initialize the Population, Particles, Particles' bounds, Velocities, Velocity bounds, acceleration constants, iterations number.

2. Initializing randomly the positions of ' $i$ ' particles in ' $d$ ' dimensions as $P_{i}^{(t)}$. Consider the initial $p_{\text {best }_{i}}$ as position of $i^{\text {th }}$ particle.

3. Calculate the Fitness function of each individual using $\mathrm{F}_{\text {cost }}$ and $\mathrm{P}_{\mathrm{c}}$.

4. Now maximum fitness value among the ' $i$ individuals is considered as the best fitness and corresponding particle is $g_{\text {best }_{d}}$.

5. Modify the velocities of the particles by using the velocity equation

$$
\begin{gathered}
v_{i d}^{(t+1)}=w^{(t+1)} \cdot v_{i d}^{(t)} \\
+c_{1} * \operatorname{rand}_{1} *\left(\text { pbest }_{i d}-x_{i d}^{(t)}\right) \\
+c_{2} * \text { rand }_{2} *\left(\text { gbest }_{d}-x_{i d}^{(t)}\right)
\end{gathered}
$$

6. Maintain the velocities within the limits such that

$$
v_{i d}^{(t+1)}= \begin{cases}v_{i_{\min }}, & \text { if } v_{i d}^{(t+1)}<v_{i_{\min }} \\ v_{i_{\max }}, & \text { if } v_{i d}^{(t+1)}>v_{i_{\max }}\end{cases}
$$

7. Update the positions of the particles, considering their bounds, using

\begin{tabular}{|c|c|c|c|}
\hline \multicolumn{4}{|c|}{ Table 6: Comparison of all Methods } \\
\hline \multirow{2}{*}{ Method } & \multicolumn{3}{|c|}{ TFC for 24 Hours, \$ } \\
\cline { 2 - 4 } & Without SUC & SUC & With SUC \\
\hline PSO-ED & 640842.2 & 5060 & 645902 \\
\hline PSO-UC & 544601.4 & 13540 & 558141.4 \\
\hline UCED & 544084.7 & 7720 & 551804.7 \\
\hline \multicolumn{4}{|c|}{$P_{i d}^{(t+1)}=P_{i d}^{(t)}+v_{i d}^{(t+1)}$} \\
\hline
\end{tabular}

8. Now evaluate the new fitness function using $P_{i d}^{(t+1)}$, then obtain the new $p_{\text {best }}$ id by comparing old fitness value with new fitness value. And again obtain the $g_{\text {best }_{d}}$.

9. The stopping criterion is the total number of iterations. Among the whole of iterations, the global best value is the optimal value.

\section{CASE STUDY AND RESULTS}

Consider the ten-unit power system $[3,7]$ as case study with generator and load data given in Tables 1 and 2 respectively.

Here transmission losses are not considered. Also the reserve power is zero. From Table 1, it is to be noted that Units 1 and 2 are in hot state and the remaining units are in cold state at the beginning. Optimal power flows over one day are computed for ED, UC and UCED methods and shown in Tables 3, 4 and 5 respectively. Resulting fuel costs of these methods are compared in Table 6. Clearly UCED is the most economical one with TFC of $\$ 544084.7$ without SUC and $\$ 551804.7$ with SUC for 24 Hours.

\section{CONCLUSIONS}

Economic dispatch of a ten-unit power system is studied by ED, UC and UCED methods. ED and UC methods are solved by PSO algorithm. In UCED, units are committed like in UC. 
Efficiency (like full load IFC) may be considered while committing units of similar capacity. Then the objective function is optimized using coordination equation of ED method for the committed units. The results for one day show that UCED is more economical than ED and UC methods as shown in Fig. 1 and Table 6. It is to be noted that this result is even better than the result of [3], where TFC for 24 hours with SUC was $\$ 557698.344$ using HGAPSO method.
In this paper transmission losses are not considered. The same will be considered in next paper as future extension.

\section{ACKNOWLEDGMENT}

The authors greatly acknowledge Siddhartha Academy of General and Technical Education, Vijayawada for providing the facilities to carry out this research.

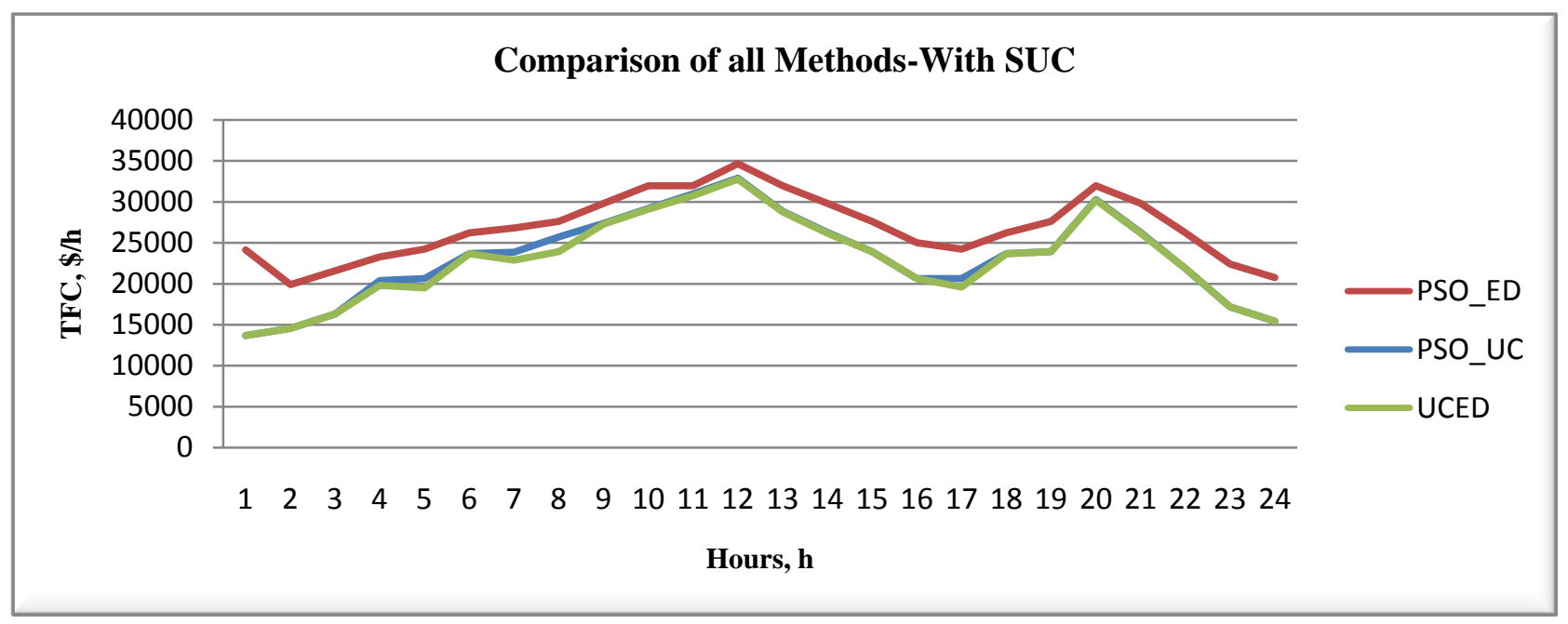

Fig. 1 Comparison of all Methods-With SUC

\section{REFERENCES}

[1] Allen J. Wood and Bruce F. Wollenberg "Power Generation Operation and Control" second edition, Wiley India, New Delhi, 2012.

[2] M. S. Krishnarayalu, "Unit Commitment with Economic Dispatch", International Electrical Engineering Journal, Vol. 6 (2015) No.5, pp.1913-1916.

[3] Mohammad Reza Salimian and Mohammad Taghi Ameli, "HGAPSO based Method for Solving Unit Commitment Problem", International Electrical Engineering Journal, Vol.6 (2015) No.3, pp.1834-1840.

[4] Cheng-Chien Kuo, "A Novel Coding Scheme for Practical Economic Dispatch by Modified Particle Swarm Approach", IEEE Transactions on Power Systems, Vol. 23, No. 4, November 2008, pp. 18251835.

[5] Zwe-Lee Gaing, "Particle Swarm Optimization to Solving the Economic Dispatch Considering the Generator Constraints", IEEE Transactions on Power Systems, Vol. 18, No. 3, August 2003, pp. 1187-1195.

[6] L. V. Narasimha Rao, "PSO Technique for Solving the Economic Dispatch Problem Considering the Generator
Constraints", International Journal of Advanced Research in Electrical, Electronics and Instrumentation Engineering, Vol. 3, Issue 7, July 2014, pp.10439-10454.

[7] T. O. Ting, M. V. C. Rao and C. K. Loo, "A Novel Approach for Unit Commitment Problem via an Effective Hybrid Particle Swarm Optimization", IEEE Transactions on Power Systems, Vol. 21, No. 1, February 2006, pp.411-418.

[8] R. Jahani, H. Chahkandi Nejad, A.H. Araskalaei and M. Hajinasiri, "A Solution to The Unit Commitment Problem Using Hybrid Genetic and particle swarm optimization Algorithms", Australian Jouranl of Basic and Applied Sciences,5(5), 2011, ISSN: 1991-8178, pp.628-634.

[9] Amita Mohar, Vishnu Prasad, Saroj Rangnekar, "Economic Dispatch using particle swarm optimization: A review", Elsevier Transactions on Renewable and Sustainable Energy Reviews, 13(2009), pp.2134-2141.

[10] V.Karthikeyan, S.Senthilkumar and V.J.Vijayalakshmi, "A New Approach to the Solution of Economic Dispatch Using Particle Swarm Optimization with Simulated Annealing", International Journal on Computational Sciences \& Applications (IJCSA) Vol.3, No.3, June 2013, pp.37-49.

\section{APPENDIX}

\begin{tabular}{|c|c|c|c|c|c|c|c|}
\hline \multicolumn{7}{|c|}{ Table 1: Generator Data } \\
\hline \multirow{2}{*}{ Unit } & $\boldsymbol{P}_{\boldsymbol{G}_{\max }}$ & $\boldsymbol{P}_{\boldsymbol{G}_{\min }}$ & \multicolumn{2}{|c|}{ Fuel cost coefficients } & $\begin{array}{c}\text { Cold Start } \\
\text { Up cost, \$ }\end{array}$ & $\begin{array}{c}\text { Initial } \\
\text { Status, h }\end{array}$ \\
\cline { 4 - 6 } & $\boldsymbol{M} \boldsymbol{M W}$ & $\boldsymbol{a}$ & $\boldsymbol{b}$ & $\boldsymbol{c}$ & & \\
\hline 1 & 455 & 150 & 1000 & 16.19 & 0.00048 & 9000 & 8 \\
\hline 2 & 455 & 150 & 970 & 17.26 & 0.00031 & 10000 & 8 \\
\hline
\end{tabular}




\begin{tabular}{|c|c|c|c|c|c|c|c|}
\hline \multicolumn{7}{|c|}{ Table 1: Generator Data } \\
\hline \multirow{2}{*}{ Unit } & $\boldsymbol{P}_{\boldsymbol{G}_{\max }}$ & \multirow{\boldsymbol{P}_{\boldsymbol{G}}\boldsymbol{M}\boldsymbol{W}}{\boldsymbol{M}\boldsymbol{W}}{} & \multicolumn{2}{|c|}{ Fuel cost coefficients } & $\begin{array}{c}\text { Cold Start } \\
\text { Up cost, \$ }\end{array}$ & $\begin{array}{c}\text { Initial } \\
\text { Status, h }\end{array}$ \\
\cline { 5 - 8 } & 130 & 20 & 700 & 16.60 & 0.002 & 1100 & -5 \\
\hline 3 & 130 & 20 & 680 & 16.50 & 0.00211 & 1120 & -5 \\
\hline 5 & 162 & 25 & 450 & 19.70 & 0.00398 & 1800 & -6 \\
\hline 6 & 80 & 20 & 370 & 22.26 & 0.00712 & 340 & -3 \\
\hline 7 & 85 & 25 & 480 & 27.74 & 0.0079 & 520 & -3 \\
\hline 8 & 55 & 10 & 660 & 25.92 & 0.00413 & 60 & -1 \\
\hline 9 & 55 & 10 & 665 & 27.27 & 0.00222 & 60 & -1 \\
\hline 10 & 55 & 10 & 670 & 27.79 & 0.00173 & 60 & -1 \\
\hline
\end{tabular}

\begin{tabular}{|c|c|c|c|}
\hline \multicolumn{4}{|c|}{ Table 2: Load Data } \\
\hline Hour & $\begin{array}{c}\text { Load } \\
\text { MW }\end{array}$ & Hour & $\begin{array}{c}\text { Load } \\
\text { MW }\end{array}$ \\
\hline 1 & 700 & 13 & 1400 \\
\hline 2 & 750 & 14 & 1300 \\
\hline 3 & 850 & 15 & 1200 \\
\hline 4 & 950 & 16 & 1050 \\
\hline 5 & 1000 & 17 & 1000 \\
\hline 6 & 1100 & 18 & 1100 \\
\hline 7 & 1150 & 19 & 1200 \\
\hline 8 & 1200 & 20 & 1400 \\
\hline 9 & 1300 & 21 & 1300 \\
\hline 10 & 1400 & 22 & 1100 \\
\hline 11 & 1450 & 23 & 900 \\
\hline 12 & 1500 & 24 & 800 \\
\hline
\end{tabular}

\begin{tabular}{|c|c|c|c|c|c|c|c|c|c|c|c|c|}
\hline \multicolumn{13}{|c|}{ Table 3: PSO applied to ED } \\
\hline $\begin{array}{l}\text { LOAD } \\
\text { MW }\end{array}$ & $\begin{array}{c}P_{1} \\
\text { MW }\end{array}$ & $\begin{array}{c}P_{2} \\
M W\end{array}$ & $\begin{array}{c}P_{3} \\
\mathrm{MW}\end{array}$ & $\begin{array}{c}P_{4} \\
\text { MW }\end{array}$ & $\begin{array}{c}P_{5} \\
M W\end{array}$ & $\begin{array}{c}P_{6} \\
\text { MW }\end{array}$ & $\begin{array}{c}P_{7} \\
\text { MW }\end{array}$ & $\begin{array}{c}P_{8} \\
\text { MW }\end{array}$ & $\begin{array}{c}P_{9} \\
\text { MW }\end{array}$ & $\begin{array}{l}P_{10} \\
\text { MW }\end{array}$ & $\begin{array}{c}\text { TFC } \\
\$ / h\end{array}$ & $\begin{array}{l}\text { Cold Start } \\
\text { Up cost, } \$\end{array}$ \\
\hline 700 & 410 & 150 & 20 & 20 & 25 & 20 & 25 & 10 & 10 & 10 & $\begin{array}{c}19075.28 \\
8\end{array}$ & 5060 \\
\hline 750 & 455 & 150 & 25 & 20 & 25 & 20 & 25 & 10 & 10 & 10 & $\begin{array}{c}19905.97 \\
2\end{array}$ & 0 \\
\hline 850 & 455 & 150 & 62.2733 & 82.7267 & 25 & 20 & 25 & 10 & 10 & 10 & $\begin{array}{c}21579.80 \\
2\end{array}$ & 0 \\
\hline 950 & 440 & 150 & 130 & 130 & 25 & 20 & 25 & 10 & 10 & 10 & $\begin{array}{c}23282.04 \\
3\end{array}$ & 0 \\
\hline 1000 & 455 & 150 & 130 & 130 & 60 & 20 & 25 & 10 & 10 & 10 & 24232.67 & 0 \\
\hline
\end{tabular}




\begin{tabular}{|c|c|c|c|c|c|c|c|c|c|c|c|c|}
\hline \multicolumn{13}{|c|}{ Table 3: PSO applied to ED } \\
\hline $\begin{array}{c}\text { LOAD } \\
\text { MW }\end{array}$ & $\begin{array}{c}P_{1} \\
\text { MW }\end{array}$ & $\begin{array}{c}P_{2} \\
\text { MW }\end{array}$ & $\begin{array}{c}P_{3} \\
\text { MW }\end{array}$ & $\begin{array}{c}P_{4} \\
\text { MW }\end{array}$ & $\begin{array}{c}P_{5} \\
M W\end{array}$ & $\begin{array}{c}P_{6} \\
\text { MW }\end{array}$ & $\begin{array}{c}P_{7} \\
\text { MW }\end{array}$ & $\begin{array}{c}P_{8} \\
\text { MW }\end{array}$ & $\begin{array}{c}P_{9} \\
\text { MW }\end{array}$ & $\begin{array}{l}P_{10} \\
\text { MW }\end{array}$ & $\begin{array}{c}\text { TFC } \\
\$ / h\end{array}$ & $\begin{array}{l}\text { Cold Start } \\
\text { Up cost, } \$\end{array}$ \\
\hline & & & & & & & & & & & 8 & \\
\hline 1100 & 455 & 455 & 130 & 130 & 25 & 20 & 25 & 10 & 10 & 10 & $\begin{array}{c}26212.87 \\
6\end{array}$ & 0 \\
\hline 1150 & 455 & 455 & 59.6978 & 80.3022 & 25 & 20 & 25 & 10 & 10 & 10 & $\begin{array}{c}26817.08 \\
4\end{array}$ & 0 \\
\hline 1200 & 455 & 385 & 130 & 130 & 25 & 20 & 25 & 10 & 10 & 10 & $\begin{array}{c}27626.41 \\
2\end{array}$ & 0 \\
\hline 1300 & 455 & 440 & 130 & 130 & 25 & 20 & 25 & 10 & 55 & 10 & $\begin{array}{c}29823.42 \\
2\end{array}$ & 0 \\
\hline 1400 & $\begin{array}{c}454.666 \\
2\end{array}$ & 455 & 115.9859 & $\begin{array}{c}124.410 \\
5\end{array}$ & 71.31 & 80 & 25 & 51.0336 & 10.7106 & 11.883 & $\begin{array}{c}31966.66 \\
2\end{array}$ & 0 \\
\hline 1450 & 455 & 455 & 112.5512 & $\begin{array}{c}124.410 \\
5 \\
\end{array}$ & 71.31 & 80 & 25 & 51.0336 & 10.7106 & 11.883 & $\begin{array}{c}31966.66 \\
2 \\
\end{array}$ & 0 \\
\hline 1500 & 455 & 443.9 & 126.9 & 104 & 121.8 & 44.5 & 77.3 & 37.8 & 47.4 & 41.1 & $\begin{array}{c}34669.17 \\
8\end{array}$ & 0 \\
\hline 1400 & $\begin{array}{c}454.666 \\
2\end{array}$ & 455 & 115.9859 & $\begin{array}{c}124.410 \\
5\end{array}$ & 71.31 & 80 & 25 & 51.0336 & 10.7106 & 11.883 & $\begin{array}{c}31966.66 \\
2\end{array}$ & 0 \\
\hline 1300 & 455 & 440 & 130 & 130 & 25 & 20 & 25 & 10 & 55 & 10 & $\begin{array}{c}29823.42 \\
2\end{array}$ & 0 \\
\hline 1200 & 455 & 385 & 130 & 130 & 25 & 20 & 25 & 10 & 10 & 10 & $\begin{array}{c}27626.41 \\
2\end{array}$ & 0 \\
\hline 1050 & 455 & 235 & 130 & 130 & 25 & 20 & 25 & 10 & 10 & 10 & $\begin{array}{c}25008.58 \\
2 \\
\end{array}$ & 0 \\
\hline 1000 & 455 & 150 & 130 & 130 & 60 & 20 & 25 & 10 & 10 & 10 & $\begin{array}{c}24232.67 \\
8\end{array}$ & 0 \\
\hline 1100 & 455 & 455 & 130 & 130 & 25 & 20 & 25 & 10 & 10 & 10 & $\begin{array}{c}26212.87 \\
6\end{array}$ & 0 \\
\hline 1200 & 455 & 385 & 130 & 130 & 25 & 20 & 25 & 10 & 10 & 10 & $\begin{array}{c}27626.41 \\
2\end{array}$ & 0 \\
\hline 1400 & $\begin{array}{c}454.666 \\
2\end{array}$ & 455 & 115.9859 & $\begin{array}{c}124.410 \\
5\end{array}$ & 71.31 & 80 & 25 & 51.0336 & 10.7106 & 11.883 & $\begin{array}{c}31966.66 \\
2\end{array}$ & 0 \\
\hline 1300 & 455 & 440 & 130 & 130 & 25 & 20 & 25 & 10 & 55 & 10 & $\begin{array}{c}29823.42 \\
2\end{array}$ & 0 \\
\hline 1100 & 455 & 455 & 130 & 130 & 25 & 20 & 25 & 10 & 10 & 10 & $\begin{array}{c}26212.87 \\
6\end{array}$ & 0 \\
\hline 900 & 455 & 150 & 87.9441 & $\begin{array}{c}107.055 \\
9\end{array}$ & 25 & 20 & 25 & 10 & 10 & 10 & $\begin{array}{c}22424.82 \\
3 \\
\end{array}$ & 0 \\
\hline 800 & 400 & 150 & 20 & 130 & 25 & 20 & 25 & 10 & 10 & 10 & $\begin{array}{c}20759.31 \\
5 \\
\end{array}$ & 0 \\
\hline & & & & & & & & & & Total & 640842.2 & 5060 \\
\hline & & & & & & & & & & & cand Total & 645902.2 \\
\hline
\end{tabular}

\begin{tabular}{|c|c|c|c|c|c|c|c|c|c|c|c|c|}
\hline \multicolumn{13}{|c|}{ Table 4: PSO applied to UC } \\
\hline $\begin{array}{c}\text { LOAD } \\
\text { MW }\end{array}$ & $\begin{array}{c}P_{1} \\
M W\end{array}$ & $\begin{array}{c}P_{2} \\
M W\end{array}$ & $\begin{array}{c}P_{3} \\
M W\end{array}$ & $\begin{array}{c}P_{4} \\
\text { MW }\end{array}$ & $\begin{array}{c}P_{5} \\
M W\end{array}$ & $\begin{array}{c}P_{6} \\
M W\end{array}$ & $\begin{array}{c}P_{7} \\
M W\end{array}$ & $\begin{array}{c}\boldsymbol{P}_{\mathbf{8}} \\
\mathbf{M W}\end{array}$ & $\begin{array}{c}P_{9} \\
M W\end{array}$ & $\begin{array}{c}P_{10} \\
\text { MW }\end{array}$ & $\begin{array}{c}\text { TFC } \\
\$ / h\end{array}$ & $\begin{array}{c}\text { Cold } \\
\text { Start Up } \\
\text { Cost, } \$\end{array}$ \\
\hline 750 & 454.5462 & 295.4537 & 0 & 0 & 0 & 0 & 0 & 0 & 0 & 0 & 14554.487 & 0 \\
\hline 850 & 454.6477 & 395.3523 & 0 & 0 & 0 & 0 & 0 & 0 & 0 & 0 & 16302.199 & 0 \\
\hline 950 & 455 & 455 & 0 & 0 & 40 & 0 & 0 & 0 & 0 & 0 & 18597.668 & 1800 \\
\hline 1000 & 455 & 415 & 0 & 130 & 0 & 0 & 0 & 0 & 0 & 0 & 19512.770 & 1120 \\
\hline 1100 & 451.4214 & 455 & 0 & 130 & 63.5786 & 0 & 0 & 0 & 0 & 0 & 21873.050 & 1800 \\
\hline 1150 & 455 & 435 & 130 & 130 & 0 & 0 & 0 & 0 & 0 & 0 & 22755.041 & 1100 \\
\hline 1200 & 455 & 455 & 0 & 130 & 160 & 0 & 0 & 0 & 0 & 0 & 23917.847 & 1800 \\
\hline 1300 & 452.1285 & 455 & 118.4734 & 122.7653 & 151.6324 & 0 & 0 & 0 & 0 & 0 & 26266.393 & 1100 \\
\hline 1400 & 443 & 455 & 130 & 130 & 162 & 80 & 0 & 0 & 0 & 0 & 28848.525 & 340 \\
\hline 1450 & 444 & 455 & 130 & 130 & 162 & 80 & 0 & 0 & 0 & 49 & 30901.005 & 60 \\
\hline 1500 & 450 & 455 & 130 & 130 & 162 & 80 & 0 & 38 & 0 & 55 & 32819.463 & 60 \\
\hline 1400 & 443 & 455 & 130 & 130 & 162 & 80 & 0 & 0 & 0 & 0 & 28848.525 & 0 \\
\hline 1050 & 455 & 455 & 0 & 0 & 140 & 0 & 0 & 0 & 0 & 0 & 20639.308 & 0 \\
\hline 1000 & 455 & 415 & 0 & 130 & 0 & 0 & 0 & 0 & 0 & 0 & 19512.770 & 1120 \\
\hline 1100 & 451.4214 & 455 & 0 & 130 & 63.5786 & 0 & 0 & 0 & 0 & 0 & 21873.050 & 1800 \\
\hline 1200 & 455 & 455 & 0 & 130 & 160 & 0 & 0 & 0 & 0 & 0 & 23917.847 & 0 \\
\hline
\end{tabular}




\begin{tabular}{|c|c|c|c|c|c|c|c|c|c|c|c|c|}
\hline 1400 & 443 & 455 & 130 & 130 & 162 & 80 & 0 & 0 & 0 & 0 & 28848.525 & 1440 \\
\hline 1300 & 452.1285 & 455 & 118.4734 & 122.7653 & 151.6324 & 0 & 0 & 0 & 0 & 0 & 26266.393 & 0 \\
\hline 1100 & 451.4214 & 455 & 0 & 130 & 63.5786 & 0 & 0 & 0 & 0 & 0 & 21873.050 & 0 \\
\hline 900 & 454.4416 & 445.5584 & 0 & 0 & 0 & 0 & 0 & 0 & 0 & 0 & 17178.417 & 0 \\
\hline 800 & 454.7395 & 345.2615 & 0 & 0 & 0 & 0 & 0 & 0 & 0 & 0 & 15427.641 & 0 \\
\hline \multicolumn{9}{|r|}{ Grand Total } & $\mathbf{5 5 8 1 4 1 . 4}$ \\
\hline
\end{tabular}

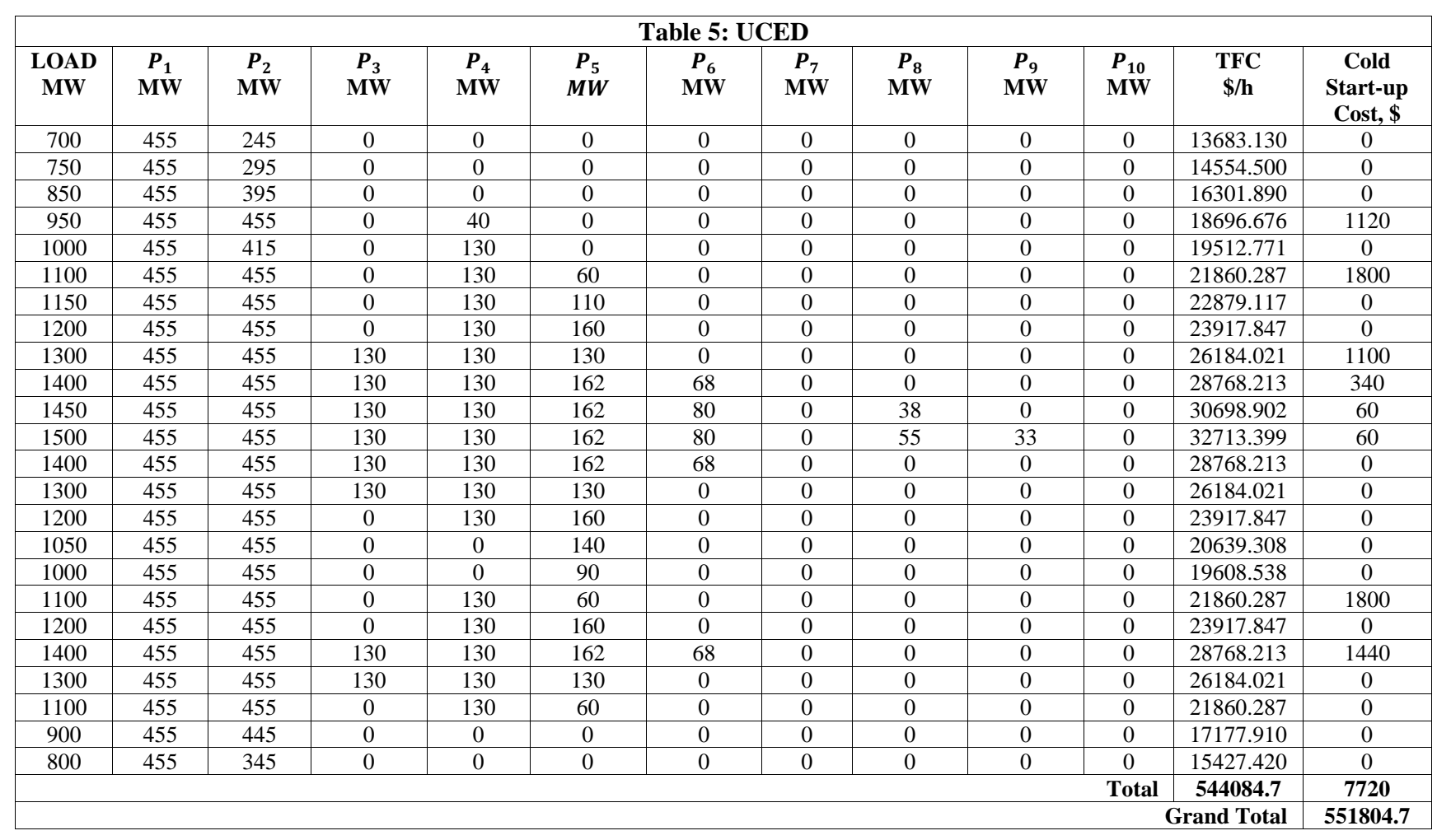

